\title{
Alkaline nanoparticle coatings improve resin bonding of I0-methacryloyloxydecyldihydrogen- phosphate-conditioned zirconia
}

This article was published in the following Dove Press journal:

International Journal of Nanomedicine

6 October 2016

Number of times this article has been viewed

\author{
Mengke Qian' \\ Zhicen Lu' \\ Chen Chen ${ }^{2}$ \\ Huaiqin Zhang' \\ Haifeng $X^{\prime}{ }^{\prime}$ \\ 'Department of Prosthodontics, \\ ${ }^{2}$ Department of Endodontics, Jiangsu \\ Key Laboratory of Oral Diseases, \\ Affiliated Hospital of Stomatology, \\ Nanjing Medical University, Nanjing, \\ People's Republic of China
}

\begin{abstract}
Creating an alkaline environment prior to 10-methacryloyloxydecyldihydroge nphosphate (MDP) conditioning improves the resin bonding of zirconia. The present study evaluated the effects of four alkaline coatings with different water solubilities and $\mathrm{pH}$ values on resin bonding of MDP-conditioned zirconia. Two alkaline nanoparticle coatings were studied in particular. Thermodynamics calculations were performed to evaluate the strengths of MDPtetragonal phase zirconia chemical bonds at different $\mathrm{pH}$ values. Zirconia surfaces with and without alkaline coatings were characterized by scanning electron microscope (SEM)/energy dispersive spectrometer and Fourier transform infrared spectroscopy; alkaline coatings included $\mathrm{NaOH}, \mathrm{Ca}(\mathrm{OH})_{2}$, nano- $\mathrm{MgO}$, and nano- $\mathrm{Zr}(\mathrm{OH})_{4}$. A shear bond strength (SBS) test was performed to evaluate the effects of the four alkaline coatings on bonding; the alkaline coatings were applied to the surfaces prior to conditioning the zirconia with MDP-containing primers. Gibbs free energies of the MDP-tetragonal zirconia crystal model coordination reaction in different $\mathrm{pH}$ environments were $-583.892(\mathrm{NaOH}),-569.048\left[\mathrm{Ca}(\mathrm{OH})_{2}\right],-547.393(\mathrm{MgO})$, and $-530.279 \mathrm{~kJ} / \mathrm{mol}$ $\left[\mathrm{Zr}(\mathrm{OH})_{4}\right]$. Thermodynamic calculations indicated that the alkaline coatings improved bonding in the following order: $\mathrm{NaOH}>\mathrm{Ca}(\mathrm{OH})_{2}>\mathrm{MgO}>\mathrm{Zr}(\mathrm{OH})_{4}$. Statistical analysis of SBS tests showed a different result. SBSs were significantly different in groups that had different alkaline coatings, but it was not influenced by different primers. All four alkaline coatings increased SBS compared to control groups. Of the four coatings, nano- $\mathrm{Zr}(\mathrm{OH})_{4}$ and $-\mathrm{MgO}$ showed higher SBS. Therefore, preparing nano- $\mathrm{Zr}(\mathrm{OH})_{4}$ or - $\mathrm{MgO}$ coatings prior to conditioning with MDP-containing primers may potentially improve resin bonding of zirconia in the clinic.
\end{abstract}

Keywords: adhesion, T-YZP, zirconia primer, bond strength, surface conditioning, MDP

\section{Introduction}

A combination of a phosphate ester monomer 10-methacryloyloxydecyldihydrogenphosphate (MDP)-containing primer, adhesive, and cement is useful for improving resin bonding of zirconia because of its simple handling and positive, stabilizing effect. ${ }^{1-5}$ According to prior literature reports, MDP-containing primers improved the resin bond strength of zirconia better than the more commonly used protocol of applying a tribochemical silica coating followed by silanization. Therefore, MDP-containing primers are recommended for bonding zirconia for clinical use. ${ }^{6-8}$

Using MDP to chemically condition zirconia creates a "reactive" ceramic surface that facilitates chemical bonding to resin; this bonding is facilitated by the dual functional groups of MDP. At one terminus, MDP possesses a phosphoric acid functional group that facilitates adhesion to zirconia. At the other terminus, MDP possesses an ethylene group that facilitates cross-linking to the unsaturated carbon bonds of the organic resin 
matrix, such as bisphenol-A-diglycidyl-methacrylate, in the resin composite cement. ${ }^{9,10}$ Additional polymerization of the carbon chain was achieved or accelerated by light or chemical activation. Chemical coordination bonds between the phosphoric acid functional group and zirconia contributed to the formation of "-Zr-O-P-." "11-14 These chemical properties of MDP result in improved bonding of zirconia to resin.

An important factor is $\mathrm{pH}$, which may affect the rate of a chemical reaction. Our earlier study found that the resin bond strength of zirconia was improved by creating an alkaline environment ( $\mathrm{pH}=11.6$ ) on the yttria-stabilized tetragonal zirconia polycrystals (Y-TZP) surface prior to application of one of two brands of MDP-containing primers; in contrast, an acidic environment $(\mathrm{pH}=3.5)$ led to a decrease in bond strength. ${ }^{15}$ That study suggested that alkaline environments may promote chemical coordination between MDP and tetragonal $(\mathrm{t})-\mathrm{ZrO}_{2}$; therefore, a protocol was proposed that creates an alkaline environment prior to conditioning zirconia with MDP-containing products in the clinic (Figure 1). To date, there is no conclusive evidence or consensus regarding what $\mathrm{pH}$ values or alkaline substances improve the bonding of zirconia to resin the most. In addition, although our previous study confirmed that an $\mathrm{NaOH}$ coating can significantly improve the bonding of MDP to zirconia, micro-leakage of the bonding interface between the resin and zirconia cannot be avoided with the existing bonding technology because the oral cavity is a moist environment. ${ }^{16,17}$ The moist, oral cavity leads to the dissolution of a water-soluble alkaline substance (eg, $\mathrm{NaOH}$ ), therefore, this environment could not maintain a stable alkalinity. To avoid this problem, the authors investigated the creation of a stable alkaline environment with alkaline coatings prepared from insoluble or slightly-soluble alkaline compounds that can withstand moisture. This approach may have more advantages in clinical applications. The aim of this

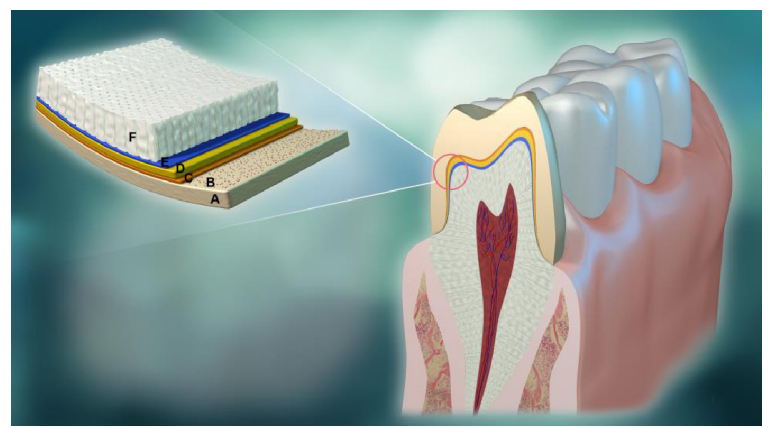

Figure I The bonding interface structure of zirconia restoration to tooth substrate.

Notes: (A) Zirconia that makes the crown; (B) the red spherical particles constitute the alkaline coating; (C) MDP-containing primer or adhesive; (D) composite resin cement; (E) dentin adhesive; (F) dentin.

Abbreviation: MDP, 10-methacryloyloxydecyldihydrogenphosphate. study was to evaluate the effects of four alkaline coatings with different water solubilities and $\mathrm{pH}$ values. In particular, this study investigated the effects of two nanoparticle coatings comprising barely soluble or insoluble alkaline compounds on bonding between MDP and zirconia. The following null hypotheses were tested: 1) these alkaline coatings improve resin bonding of MDP-containing primers to zirconia and 2) different $\mathrm{pH}$ values do not provide different effects.

\section{Methods and materials}

\section{Theory evaluating the strengthening of the MDP-tetragonal phase zirconia chemical bonds under different $\mathrm{pH}$ values}

The tetragonal zirconia crystal model $\left(\mathrm{t}-\mathrm{ZrO}_{2}\right)$ was based on the Inorganic Crystal Structure Database (Fachinformationszentrum Karlsruhe Information Services, EggensteinLeopoldshafen, Germany), and the MDP molecule model was based on the molecular structure from (Kuraray Noritake Dental Co., Tokyo, Japan). Interaction between MDP and $\mathrm{t}-\mathrm{ZrO}_{2}$ was calculated using a quantum mechanics/molecular mechanics (MM) approach. Density functional theory (DFT) and MM were applied for high-level and low-level calculations, respectively. DFT calculations were performed with the hybrid exchange functional of Becke's 3 parameters (B3) and the Lee-Yang-Parr's nonlocal correlation functional for finding the stable optimization geometries and calculating thermodynamics functions of the $\mathrm{t}-\mathrm{ZrO}_{2}$ cluster and phosphate head group. The following convergence criteria for optimization were used: maximum force $<0.000450$ Hartree/ Bohr; root mean square (RMS) force $<0.000300$ Hartree/ Bohr; maximum displacement $<0.001800$ Hartree/Bohr; and RMS displacement $<0.001200$ Hartree/Bohr. The basis sets for $\mathrm{C}, \mathrm{P}, \mathrm{O}$ and $\mathrm{H}$ were $6-311+\mathrm{G}^{* *}$ with polarization functions for $\mathrm{C}, \mathrm{P}, \mathrm{O}$ and $\mathrm{H}$, and with diffuse functions for $\mathrm{C}$, $\mathrm{P}$, and $\mathrm{O}$ atoms. For zirconium atoms, the valence and core electrons were described by the basis set of LanL2DZ and the corresponding relativistic effective core potential, respectively. MM calculations were performed with the universal force field for finding the stable, optimized geometries and calculating thermodynamics functions. Solvent effects were measured using the integral equation formal polarization continuum model. All calculations concerning geometry optimization and thermodynamics functions were performed with Gaussian09 software (Gaussian, Wallingford, CT, USA).

\section{Preparation and characterization of alkaline coatings}

Plates $\left(10 \times 10 \times 1.2 \mathrm{~mm}^{3}\right)$ containing Y-TZP (Everest ZSRonde, KAVO, Kaltenbach \& Voigt GmbH \& Co. KG, 
Bismarckring, Germany) were cut from a machinable Y-TZP block using a low-speed saw (Isomet 100; Buehler Ltd., IL, USA). The plates were completely sintered, according to the manufacturer's directions. Then, they were sandblasted with $110 \mu \mathrm{m}$ alumina particles from a $10 \mathrm{~mm}$ distance for 20 seconds at $0.3 \mathrm{MPa}$ using a sandblasting device (JNBP-2; Jianian Futong Medical Equipment Co., Ltd., Tianjin, People's Republic of China).

The following four alkaline compounds with different water solubilities were selected for the preparation of coating liquids: $1 \mathrm{~mol} / \mathrm{L} \mathrm{NaOH}$ solution, supersaturated $\mathrm{Ca}(\mathrm{OH})_{2}$ solution, suspension of nano-MgO particles (sizes $50 \pm 5 \mathrm{~nm}$ ), and a suspension of nano- $\mathrm{Zr}(\mathrm{OH})_{4}$ particles (sizes $50-100 \mathrm{~nm}$ ). The suspensions of nano-MgO and nano- $\mathrm{Zr}(\mathrm{OH})_{4}$ were centrifuged (Heraeus Labofuge 400; Thermo Scientific, USA) for 10 minutes and settled for 7 days; then, their supernatants were used as the coating solutions. An electronic precision $\mathrm{pH}$ meter ( $\mathrm{pH} 108$; Shanghai MiLian Electronics Technology Ltd, Shanghai, People's Republic of China) was used to measure the $\mathrm{pH}$ values of the four coating liquids. Each acquired liquid was uniformly coated on the Y-TZP plate surface with a small brush; then, the coated Y-TZP plates were hot-dried at $80^{\circ} \mathrm{C}$ in a heat oven.

The sandblasted Y-TZP surfaces comprising alkaline coatings were sputter-coated with gold and then examined with a field emission-SEM (LEO 1530VP, Oberkochen, Germany) at $15 \mathrm{kV}$. An energy dispersive spectrometer (EDS; INCAx-sight, Oxford Instruments, UK) was used to characterize the elemental distributions on the alkalinecoated Y-TZP plate surfaces that were coated with a thin carbon layer.

The surface layer of the Y-TZP plates with four alkaline coatings and the control Y-TZP plate (only received alumina sandblasting) were grounded into powders and then dried for 24 hours and examined by Fourier transform infrared spectroscopy (FTIR; NEXUS870, Nicolet, Madison, WI, USA). The optical system of the FTIR was operated in transmission mode and scanned the 4,000 to $500 \mathrm{~cm}^{-1}$ wavelength range; the wavelength range 3,600 to $3,300 \mathrm{~cm}^{-1}$ was defined as the region of interest.

\section{Particle size analysis of the supernatants for preparing $\mathrm{MgO}$ and $\mathrm{Zr}(\mathrm{OH})_{4}$ coatings}

To evaluate the particle size distribution of nano-MgO and nano- $\mathrm{Zr}(\mathrm{OH})_{4}$, supernatants used for coatings, particle size analysis was performed with a particle sizing instrument (Zetasizer Nano ZS90; Malvern Instruments Ltd., Malvern, UK). Particle sizes were analyzed for centrifuged suspensions of nano- $\mathrm{MgO}$ and nano- $\mathrm{Zr}(\mathrm{OH})_{4}$ that did not contain precipitation that forms after 7 days.

\section{Shear bond strength test and statistical analyses}

A total of $100 \mathrm{Y}$-TZP plates $\left(10 \times 10 \times 2 \mathrm{~mm}^{3}\right)$ were prepared and then randomly assigned to ten groups according to the conditioning method employed.

Groups $\mathrm{Zp}$ and Cle: The bonding surface was alumina sandblasted. A coat of Z-Prime Plus (Zp; Bisco Inc., Schaumburg, IL, USA) or Clearfil ceramic primer (Cle; Kuraray Medical Inc., Okayama, Japan) was applied to the sandblasted surface. After 15-20 seconds of volatilization, the primed Y-TZP surface was dried with low-pressure, oilfree air for 15 seconds.

Groups $\mathrm{ZpNaOH}, \mathrm{CleNaOH}, \mathrm{ZpCaOH}, \mathrm{CleCaOH}$, $\mathrm{ZpMgO}, \mathrm{CleMgO}, \mathrm{ZpZrOH}$, and $\mathrm{CleZrOH}$ : Alkaline coatings $\left[\mathrm{NaOH} / \mathrm{Ca}(\mathrm{OH})_{2} / \mathrm{MgO} / \mathrm{Zr}(\mathrm{OH})_{4}\right]$ with different $\mathrm{pH}$ values were prepared on the sandblasted Y-TZP surface according the method mentioned. Then, a coat of Z-Prime Plus or Clearfil ceramic primer was applied as described for Groups Zp and Cle.

A total of 100 light-cured resin composite cylinders (6 $\mathrm{mm}$ in inner diameter and $3 \mathrm{~mm}$ in height) were prepared via nylon models. A layer of resin composite cement was applied to the surface of the pretreated Y-TZP plate, and a resin-composite cylinder was placed on the resin cement under a constant load. Excess cement was removed, and the remaining cement was light-cured for 40 seconds with an LED light-curing unit (Elipar FreeLight 2; 3M ESPE, St Paul, MN, USA). Details of the materials used in the present study are given in Table 1.

Shear bond strength (SBS) testing was performed using a universal testing machine (Model 3365; Instron Corp., Canton, MA, USA) at a crosshead speed of $1 \mathrm{~mm} / \mathrm{min}$. All the bonded specimens were stored in distilled water at room temperature for 24 hours before testing. The failure mode of each specimen after SBS testing was observed. The modes of failure were classified as adhesive (fracture occurred at the resin/resin cement and Y-TZP interface), cohesive (fracture occurred within the resin/resin cement), and mixed (both adhesive and cohesive failure occured).

SBS mean values for each group were submitted to a two-way analysis of variance (ANOVA) and least significant difference (LSD) multiple comparison; these analyses were used to determine the effects on SBS mean values of different primers, alkaline coatings with different $\mathrm{pH}$ values, and the influence of their interaction. These statistical analyses were performed using the SPSS 19.0 statistical software 
Table I Details of the materials used in the shear bond strength

\begin{tabular}{lll}
\hline Material/trade name & Main composition* & Manufacturer \\
\hline $\begin{array}{l}\text { Zirconia primer/Z-Prime Plus } \\
\text { Zirconia primer/Clearfil }\end{array}$ & Ethanol (<90\%), biphenyl dimethacrylate (<10\%); HEMA (<20\%); MDP \\
$\begin{array}{l}\text { ceramic primer } \\
\text { Light-polymerized resin }\end{array}$ & Filler: zirconia/silica and fumed silica fillers \\
$\begin{array}{l}\text { cement/RelyX Veneer } \\
\text { Light-polymerized resin }\end{array}$ & Base resin: Bis-GMA; TEGDMA \\
composite/Valux Plus & Filler: barium aluminum fluoride glass + highly dispersive silica (80\%-90\%) & 3 M ESPE, St Paul, MN, USA \\
\hline
\end{tabular}

Note: *Details of major compositions were obtained from the material safety data sheets provided by the manufacturers.

Abbreviations: Bis-GMA, bisphenol A glycidyl dimethacrylate; HEMA, 2-hydroxylethyl methacrylate; MDP, I0-methacryloyloxydecyldihydrogenphosphate; TEGDMA, triethylene glycol dimethacrylate.

package (IBM SPSS Inc., Chicago, IL, USA). Statistical significance was preset at $\alpha=0.05$.

\section{FTIR characterization of alkaline-coated zirconia conditioned by MDP-containing primers}

Sandblasted Y-TZP plates with and without alkaline coatings were each conditioned by one of two MDP-containing primers (Z-Prime Plus or Clearfil ceramic primer), and their surface layers were grounded into powders. Then, the plates were examined by FTIR in reflection mode after 24 hours of drying. FTIR scanned a range of wavelength from 4,000 to $500 \mathrm{~cm}^{-1}$, and the 3,600 to $3,300 \mathrm{~cm}^{-1}$ wavelength range was defined as the region of interest.

\section{Results}

\section{Thermodynamic calculation results}

The optimized double MDP-t- $\mathrm{ZrO}_{2}$ coordination model and corresponding description of atoms are shown in Figure 2, and the corresponding changes of bond length are shown in Table 2. The reactions between MDP and the $\mathrm{t}-\mathrm{ZrO}_{2}$ cluster are listed by the following equations:

$$
\begin{gathered}
\mathrm{R}-\mathrm{OP}(\mathrm{OH})_{2}(\mathrm{aq})+2 \mathrm{H}_{2} \mathrm{O}(\mathrm{aq}) \\
\stackrel{\text { Dissociation }}{\longrightarrow} \mathrm{R}-\mathrm{OPO}_{2}{ }^{2-}(\mathrm{aq})+2 \mathrm{H}_{3} \mathrm{O}^{+}(\mathrm{aq}) \\
\mathrm{R}-\mathrm{OPO}_{2}{ }^{2-}+\mathrm{Zr}_{4} \mathrm{O}_{8} \stackrel{\text { Coordinate }}{\longrightarrow} \mathrm{R}-\mathrm{OPO}_{2}-\mathrm{Zr}_{4} \mathrm{O}_{8}{ }^{2-}
\end{gathered}
$$

where $\mathrm{R}$ represents the remaining structure of the MDP molecule without the phosphate head group.

Equation 1 occurs in the solvation phase and Equation 2 occurs at the interface between the solvation and solid phases. Therefore, Equation 1 considers solvation effects and added solvation Gibbs free energy. Only vacuum phase thermodynamic data were used in Equation 2 calculations because net binding energy of this coordinate reaction on the interface was the focus. There was no obvious solvation effect when the phosphate head group approached the $\mathrm{ZrO}_{2}$ crystal face because only a hydrophobic hydrocarbon chain contacted the aqueous phase. We eliminated the contribution of this in our calculations in order to enhance the accuracy because the translation entropy could not be consistently and properly estimated. The results of thermodynamic calculations are shown in Table 3.

Equation 1 (which represents the dissociation of MDP) would be affected by $\mathrm{pH}$ values. Decreasing $\mathrm{pH}$ values result in decreased dissociation of MDP, which leads to decreasing amounts of $\mathrm{R}-\mathrm{OPO}_{2}^{2-}$ that can react with $\mathrm{ZrO}_{2}$; therefore, the reactions between MDP and the $\mathrm{t}-\mathrm{ZrO}_{2}$ cluster were weakened accordingly. When the $\mathrm{pH}$ values were set as the values of the four alkaline coating liquids adopted in

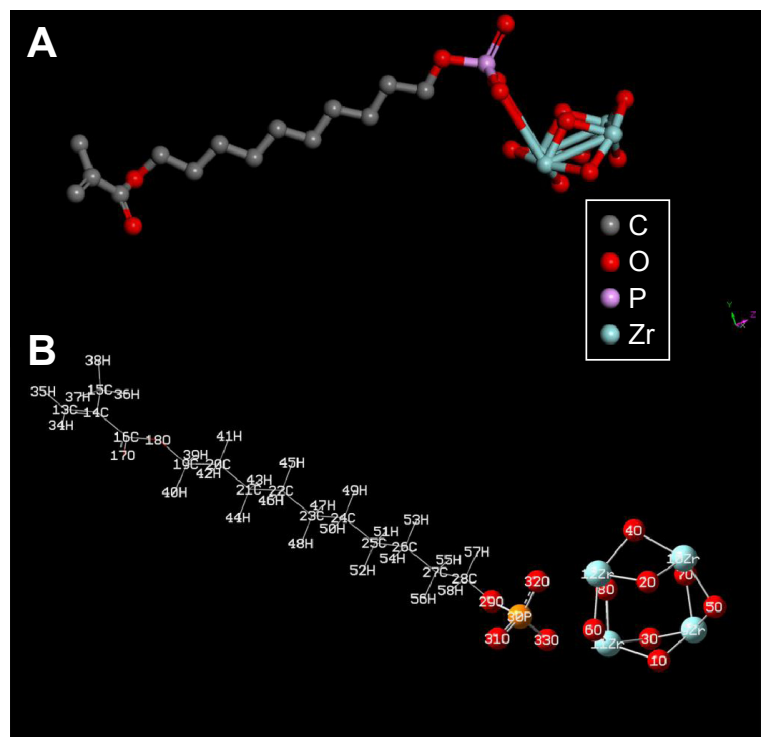

Figure 2 The MDP-t- $\mathrm{ZrO}_{2}$ coordination model after optimization (A) and description of the atom numbers in the model (B).

Abbreviations: MDP, I0-methacryloyloxydecyldihydrogenphosphate; $\mathrm{t}-\mathrm{ZrO}{ }_{2}$, tetragonal zirconia crystal model. 
Table 2 The changes of bond length in optimized double $\mathrm{MDP}-\mathrm{t}-\mathrm{ZrO}_{2}$ coordination model

\begin{tabular}{|c|c|c|c|c|c|}
\hline Atoms & $\begin{array}{l}\text { MDP before } \\
\text { optimization }\end{array}$ & $\begin{array}{l}\text { MDP after } \\
\text { optimization }\end{array}$ & $\begin{array}{l}\text { MDP }^{2-} \text { after } \\
\text { optimization }\end{array}$ & $\begin{array}{l}{\left[\mathrm{R}-\mathrm{OPO}_{2}-\mathrm{ZrO}_{2}\right]^{2-}} \\
\text { before optimization }\end{array}$ & $\begin{array}{l}{\left[\mathrm{R}-\mathrm{OPO}{ }_{2}-\mathrm{ZrO}_{2}\right]^{2-}} \\
\text { after optimization }\end{array}$ \\
\hline P30-O33 & 1.563 & 1.676 & 1.623 & 1.563 & 1.592 \\
\hline $\mathrm{P} 30-\mathrm{O} 32$ & 1.563 & 1.675 & 1.620 & 1.563 & 1.582 \\
\hline P30-O3I & $1.51 \mathrm{I}$ & $\mathrm{I} .564$ & 1.624 & $1.51 \mathrm{I}$ & 1.499 \\
\hline P30-O29 & 1.695 & 1.728 & 1.835 & 1.695 & 1.700 \\
\hline O29-C28 & 1.389 & 1.394 & 1.393 & 1.389 & 1.389 \\
\hline C28-C27 & 1.529 & 1.528 & 1.528 & 1.528 & 1.529 \\
\hline O32-ZrI2 & I & I & 1 & 2.285 & 2.195 \\
\hline O33-ZrII & I & I & 1 & 2.287 & 2.197 \\
\hline Zrll-O8 & I & I & 1 & 1.986 & 1.756 \\
\hline $\mathrm{Zr} 12-\mathrm{O} 8$ & 1 & I & 1 & 1.987 & 1.742 \\
\hline $\mathrm{ZrII-O6}$ & I & I & 1 & 2.063 & 2.108 \\
\hline $\mathrm{Zr} / 2-\mathrm{O} 6$ & I & l & l & 2.057 & 2.167 \\
\hline
\end{tabular}

Abbreviations: MDP, 10-methacryloyloxydecyldihydrogenphosphate; $\mathrm{t}-\mathrm{ZrO}_{2}$, tetragonal zirconia crystal model.

the present study, the reaction quotient $(\mathrm{Q})$ can be deduced from the following formula:

$$
\mathrm{Q}=\frac{\left[\mathrm{R}-\mathrm{OPO}_{2}^{2-}\right]\left[\mathrm{H}_{3} \mathrm{O}^{+}\right]^{2}}{\left[\mathrm{R}-\mathrm{OP}(\mathrm{OH})_{2}\right]}
$$

Assume the concentration of MDP $\left[\mathrm{R}-\mathrm{OP}(\mathrm{OH})_{2}\right]$ without dissociation was $1 \mathrm{M}$ and the concentration of dissociated $\mathrm{MDP}\left(\mathrm{R}-\mathrm{OPO}_{2}{ }^{2-}\right)$ was $1 \mathrm{M}$. Based on the above conditions, for $\mathrm{pH}=-\lg \left(\mathrm{H}^{+}\right), \mathrm{Q}$ values were $10^{-28}[\mathrm{pH}=14(\mathrm{NaOH})], 4 \times 10^{-26}$ $\left\{\mathrm{pH}=12.7\left[\mathrm{Ca}(\mathrm{OH})_{2}\right]\right\}, 2.5 \times 10^{-22}[\mathrm{pH}=10.8(\mathrm{MgO})]$, and $2.5 \times 10^{-19}\left\{\mathrm{pH}=9.3\left[\mathrm{Zr}(\mathrm{OH})_{4}\right]\right\}$. The Gibbs free energy of Equation 1 in different $\mathrm{pH}$ environments can be deduced from the following formula:

$$
\Delta_{\mathrm{r}} \mathrm{G}_{\mathrm{m}}(\mathrm{T})=\Delta_{\mathrm{r}} \mathrm{G}_{\mathrm{m}}{ }^{\theta}(\mathrm{T})+\mathrm{RT} \ln \mathrm{Q}
$$

where $\mathrm{R}$ is the universal gas constant $(8.314 \mathrm{~J} / \mathrm{K})$ and $\mathrm{T}$ is the temperature $(298 \mathrm{~K})$. The subscript $r$ represents reaction, the subscript $\mathrm{m}$ molar reaction, and the superscript $\theta$ standard situation. The calculated Gibbs free energies were $164.404 \mathrm{~kJ} / \mathrm{mol}$ $(\mathrm{NaOH}), 179.248 \mathrm{~kJ} / \mathrm{mol}\left[\mathrm{Ca}(\mathrm{OH})_{2}\right], 200.903 \mathrm{~kJ} / \mathrm{mol}(\mathrm{MgO})$, and $218.018 \mathrm{~kJ} / \mathrm{mol}\left[\mathrm{Zr}(\mathrm{OH})_{4}\right]$. Combined with the Gibbs free energy of Equation 2, the final Gibbs free energy of the MDP-t- $\mathrm{ZrO}_{2}$ coordination reaction (Equations 1+2) in different $\mathrm{pH}$ environments should be $-583.892 \mathrm{~kJ} / \mathrm{mol}$ (NaOH), $-569.048 \mathrm{~kJ} / \mathrm{mol}\left[\mathrm{Ca}(\mathrm{OH})_{2}\right],-547.393 \mathrm{~kJ} / \mathrm{mol}(\mathrm{MgO})$, and $-530.279 \mathrm{~kJ} / \mathrm{mol}\left[\mathrm{Zr}(\mathrm{OH})_{4}\right]$.

\section{Analysis of particle sizes of the supernatants for preparing $\mathrm{MgO}$ and $\mathrm{Zr}(\mathrm{OH})_{4}$ coatings}

The average diameter of the centrifuged nano-MgO supernatant was $597.5 \mathrm{~nm}$; this decreased to $229.5 \mathrm{~nm}$ after 7 days

\begin{tabular}{|c|c|c|c|c|c|c|c|}
\hline & \multicolumn{4}{|c|}{ Equation I } & \multicolumn{3}{|l|}{ Equation 2} \\
\hline & $\mathrm{H}_{2} \mathrm{O}$ & $\mathbf{H}_{3} \mathbf{O}^{+}$ & $\mathrm{R}-\mathrm{OP}(\mathrm{OH})_{2}$ & $\mathrm{R}^{-\mathrm{OPO}_{2}}{ }^{2-}$ & $\mathrm{R}^{-\mathrm{OPO}_{2}}{ }^{2-}$ & $\mathrm{t}-\mathrm{ZrO}_{2}$ & {$\left[\mathrm{R}-\mathrm{OPO}_{2}-\mathrm{ZrO}_{2}\right]^{2-}$} \\
\hline$v$ & -2 & 2 & -1 & 1 & -1 & -1 & I \\
\hline $\mathrm{S}_{\text {electron }}$ & 0 & 0 & 0 & 0 & 0 & 0 & 0 \\
\hline$S_{\text {rot }}^{\text {electron }}$ & 10.317 & 9.656 & 36.435 & 36.407 & 36.419 & 30.671 & 40.692 \\
\hline$S_{\text {vib }}^{\text {rot }}$ & 0.004 & 1.204 & 96.992 & 88.922 & 94.042 & 40.339 & 123.759 \\
\hline$S_{\text {tot }}$ & 10.321 & 10.860 & I 33.427 & 125.329 & $|30.46|$ & 71.010 & $|64.45|$ \\
\hline$\varepsilon_{0}$ & -76.021 & -76.425 & -644.025 & -643.102 & -642.745 & -788.875 & -1431.909 \\
\hline$\varepsilon_{\text {zpe }}$ & 0.022 & 0.036 & 0.425 & 0.403 & 0.403 & 0.027 & 0.407 \\
\hline$E_{\text {tot }}$ & 0.025 & 0.039 & 0.449 & 0.426 & 0.426 & 0.040 & 0.434 \\
\hline $\mathrm{H}_{\text {corr }}^{\text {tot }}$ & 0.026 & 0.040 & 0.450 & 0.427 & 0.427 & 0.042 & 0.435 \\
\hline $\mathrm{G}_{\text {corr }}^{\text {corr }}$ & 0.005 & 0.018 & 0.366 & 0.347 & 0.344 & -0.013 & 0.335 \\
\hline$\Delta \mathrm{G}(\mathrm{kJ} / \mathrm{mol})$ & \multirow{2}{*}{\multicolumn{4}{|c|}{$\begin{array}{l}324.139 \\
\text { I }\end{array}$}} & \multirow{2}{*}{\multicolumn{3}{|c|}{$\begin{array}{l}-748.296 \\
5.28 \times 10^{130}\end{array}$}} \\
\hline $\mathrm{K}$ & & & & & & & \\
\hline
\end{tabular}

Table 3 Thermodynamic calculation results of coordination configuration of $\mathrm{MDP}_{\mathrm{t}-\mathrm{ZrO}}$

Notes: $v$, stoichiometric coefficient; $\mathrm{S}_{\text {electron, }}$, entropy of an electron; $\mathrm{S}_{\text {rot }}$, rotational component of total entropy; $\mathrm{S}_{\mathrm{vib}}$, vibrational component of total entropy; $\mathrm{S}_{\text {tot }}$, total entropy; $\varepsilon_{0}$, zero point vibrational energy; $\varepsilon_{\text {zpe }}$, zero point vibrational correction; $E_{\text {tot }}$, correction to the internal thermal energy; $H_{\text {corr }}$, thermal correction to enthalpy; $G_{\text {corr }}$, thermal correction to Gibbs free energy; K, equilibrium constant.

Abbreviations: MDP, I0-methacryloyloxydecyldihydrogenphosphate; $\mathrm{t}-\mathrm{ZrO}_{2}$, tetragonal zirconia crystal model. 
of settling. Similarly, the average diameter of the centrifuged nano- $\mathrm{Zr}(\mathrm{OH})_{4}$ supernatant was $458.1 \mathrm{~nm}$; this decreased to $317.4 \mathrm{~nm}$ after 7 days of settling. The particle size distribution spectra are shown in Figure 3.

\section{Morphological observations and EDS analysis of alkaline coatings}

Typical SEM images of the four coated Y-TZP surfaces under $\times 20,000$ magnifications are shown in Figure 4A-D. Spheroidal particles with sizes under hundreds of nanometer can be observed on the Y-TZP surfaces with $\mathrm{MgO}$ or $\mathrm{Zr}(\mathrm{OH})_{4}$ coatings; these particle sizes are consistent with the size scales of $\mathrm{MgO}$ or $\mathrm{Zr}(\mathrm{OH})_{4}$ supernatants. On the $\mathrm{Ca}(\mathrm{OH})_{2}$-coated Y-TZP surface, numbers of polyhedron-shaped crystals can be observed. On the $\mathrm{NaOH}$-coated Y-TZP surface, cluster-like crystals can be observed.

$\mathrm{Mg}$ was detected by EDS mapping (Figure 5) on the $\mathrm{MgO}$-coated Y-TZP surface. Ca was detected on the $\mathrm{Ca}(\mathrm{OH})_{2}-$ coated surface. $\mathrm{Na}$ was detected on the $\mathrm{NaOH}$-coated surface. The distributions of $\mathrm{Mg}, \mathrm{Ca}$, and $\mathrm{Na}$ were consistent with the distribution of the corresponding particles or crystals on the $\mathrm{MgO}-, \mathrm{Ca}(\mathrm{OH})_{2}$-, and $\mathrm{NaOH}$-coated surfaces. The distribution areas of $\mathrm{Al}$ were identical, and they appeared to be pointed in shape, reflecting the points of impact with the alumina sands. ${ }^{18,19}$ EDS spectra (Figure 4E-G) showed that the contents of $\mathrm{Mg}, \mathrm{Ca}$, and $\mathrm{Na}$ were $2.4 \mathrm{wt} \%, 6.2 \mathrm{wt} \%$, and $11.6 \mathrm{wt} \%$, respectively.

\section{SBS testing}

Figure 6 shows the SBS values (mean and standard deviations) for ten groups. Mixed failure was observed in all specimens, and no adhesive or cohesive failure was found.
The Levene test showed that the SBS data normally distributed and exhibited equal variance $(F=1.165, P=0.327)$. Two-way ANOVA indicated that SBSs were significantly different in groups regardless of alkaline coating ( $F=13.470$, $P=0.000)$; however, SBSs were not influenced by different primers $(F=1.939, P=0.167)$. SBS was not affected by an interaction of the two factors $(F=0.666, P=0.617)$. LSD multiple comparisons showed that all four alkaline coatings increased SBS compared to the control groups (all $P<0.05$ ). Among the different alkaline coatings, $\mathrm{Zr}(\mathrm{OH})_{4}$ showed the highest SBS (all $P<0.001$ ). No difference in SBS was found between $\mathrm{MgO}$ and $\mathrm{NaOH}$ coatings $(P=0.245)$ nor between $\mathrm{Ca}(\mathrm{OH})_{2}$ and $\mathrm{NaOH}$ coatings $(P=0.372)$.

\section{FTIR characterization results}

FTIR spectra are shown in Figure 7A-C. In Figure 7A, the characteristic strong peaks of Y-TZP at $3,498 \mathrm{~cm}^{-1}$ correspond to the stretching vibrations of $\mathrm{O}-\mathrm{H}$ bonds. When alkaline substances such as $\mathrm{NaOH}, \mathrm{MgO}, \mathrm{Ca}(\mathrm{OH})_{2}$, and $\mathrm{Zr}(\mathrm{OH})_{4}$ are added to the surface of Y-TZP for enhancing the alkalinity of the Y-TZP surface, these absorption bands also occur, but the infrared characteristic peak is both broad and blunt. With this idea, after conditioning with Z-Primer Plus or Clearfil ceramic primer, from the Figure $7 \mathrm{~B}$ and $\mathrm{C}$, it can be found that the infrared characteristic peak become broad and blunt similarly, which indicates that the alkaline can increase the interaction of MDP with the $\mathrm{ZrO}_{4}$, such as the bond $\mathrm{Zr}-\mathrm{O}-\mathrm{P}$.

\section{Discussion}

Results of the present thermodynamic calculations indicate that alkaline conditions promote the dissociation of MDP
A
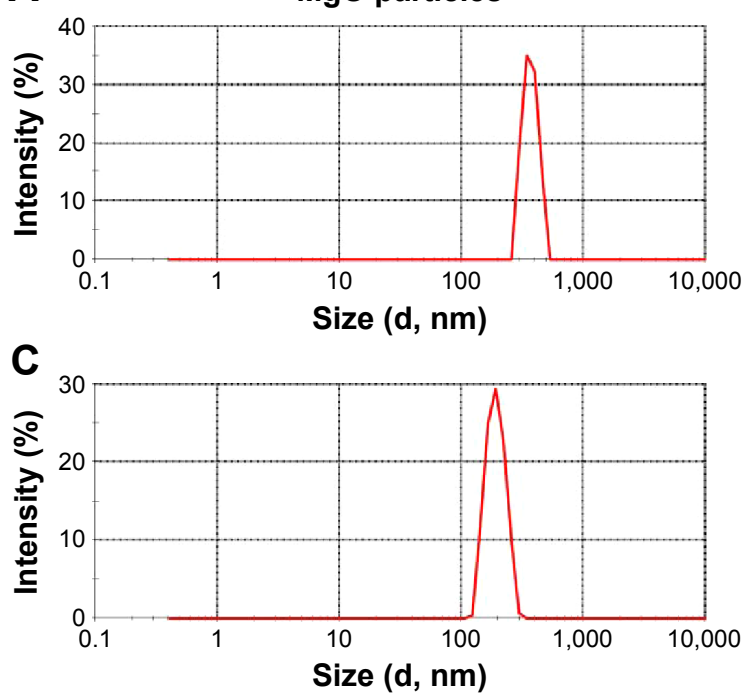

B

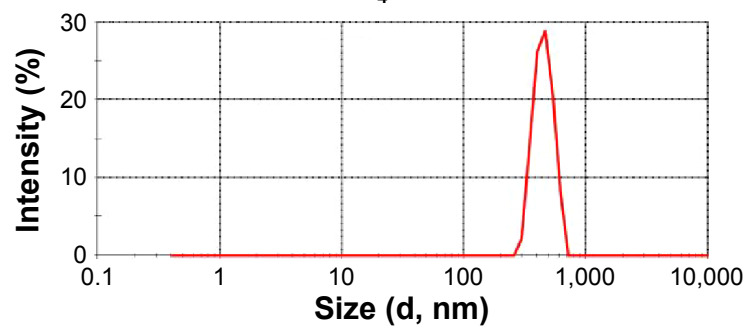

D

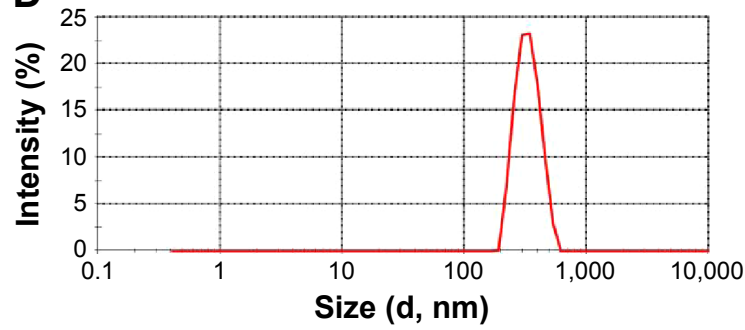

Figure 3 Particle size analysis of centrifugal supernatants of nano- $\mathrm{MgO}$ and nano- $\mathrm{Zr}(\mathrm{OH})_{4}$. Notes: (A) Nano-MgO without settling; (B) nano- $\mathrm{Zr}(\mathrm{OH})_{4}$ without settling; (C) nano-MgO after 7 days settling; (D) nano- $\mathrm{Zr}(\mathrm{OH})_{4}$ after 7 days settling. 

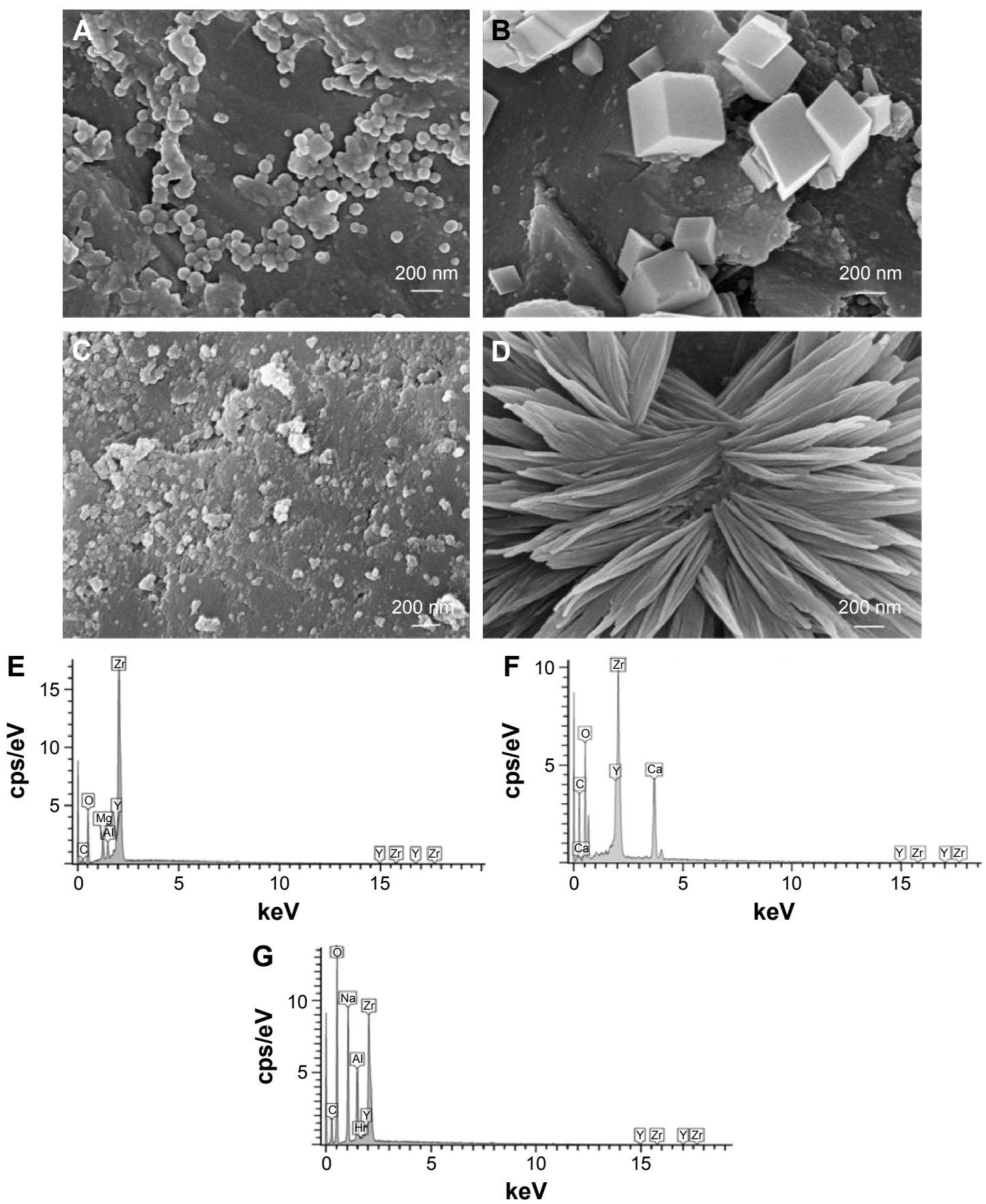

Figure 4 Typical SEM images of the four coated Y-TZP surface under $\times 20,000$ magnifications.

Notes: (A) MgO coating; (B) $\mathrm{Ca}(\mathrm{OH})_{2}$ coating; (C) $\mathrm{Zr}(\mathrm{OH})_{4}$ coating; (D) $\mathrm{NaOH}$ coating; (E) EDS spectra of MgO-coated Y-TZP surface; (F) Ca(OH) ${ }_{2}$-coated Y-TZP surface; (G) $\mathrm{NaOH}$-coated Y-TZP surface under $\times 2,000$ magnifications.

Abbreviations: SEM, scanning electron microscope; Y-TZP, yttria-stabilized tetragonal zirconia polycrystals.

compared to neutral conditions; alkaline conditions help MDP coordinate with $\mathrm{ZrO}_{2}$, because the reaction is facilitated at a higher $\mathrm{pH}$. These results support the hypothesis that the alkaline bonding conditions created by the four alkaline coatings could improve the coordination between MDP and $\mathrm{ZrO}_{2}$ and enhance the resin bonding strength of MDP-conditioned zirconia. Moreover, based on thermodynamic calculations, alkaline coatings may promote bonding in the following order: $\mathrm{NaOH}>\mathrm{Ca}(\mathrm{OH})_{2}>\mathrm{MgO}>\mathrm{Zr}(\mathrm{OH})_{4}$, according to the order of corresponding reaction quotients.

Stable alkaline environments may be obtained by applying alkaline coatings to a zirconia substrate, wherein the alkaline coating is prepared with insoluble or slightly soluble alkaline compounds that can withstand the presence of moisture. However, the $\mathrm{pH}$ of solutions decrease with an alkaline compound's lower water solubility. To obtain 

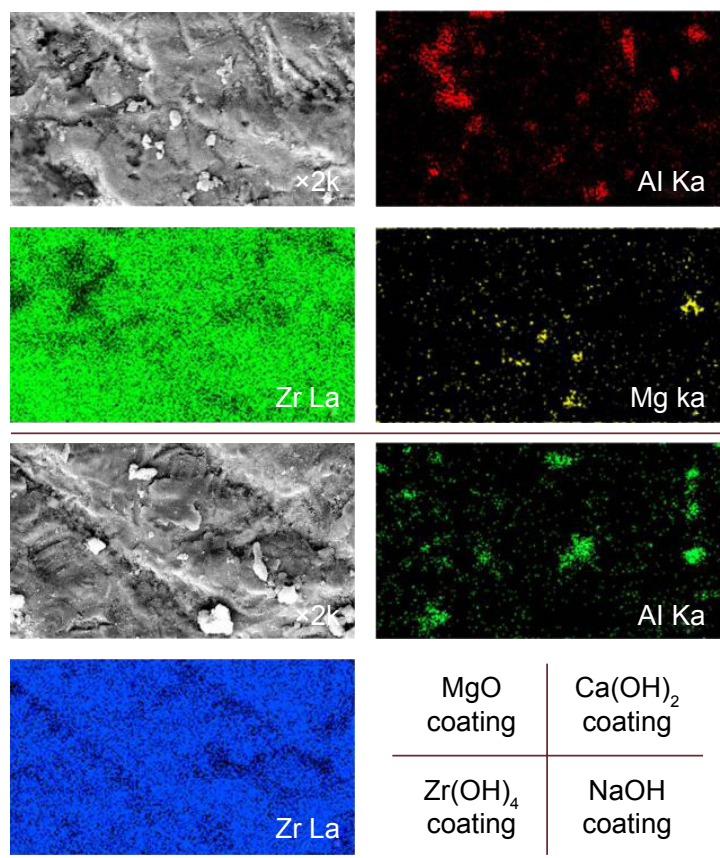

\begin{tabular}{c|c}
$\begin{array}{c}\mathrm{MgO} \\
\text { coating }\end{array}$ & $\begin{array}{c}\mathrm{Ca}(\mathrm{OH})_{2} \\
\text { coating }\end{array}$ \\
\hline $\begin{array}{c}\mathrm{Zr}(\mathrm{OH})_{4} \\
\text { coating }\end{array}$ & $\begin{array}{c}\mathrm{NaOH} \\
\text { coating }\end{array}$
\end{tabular}
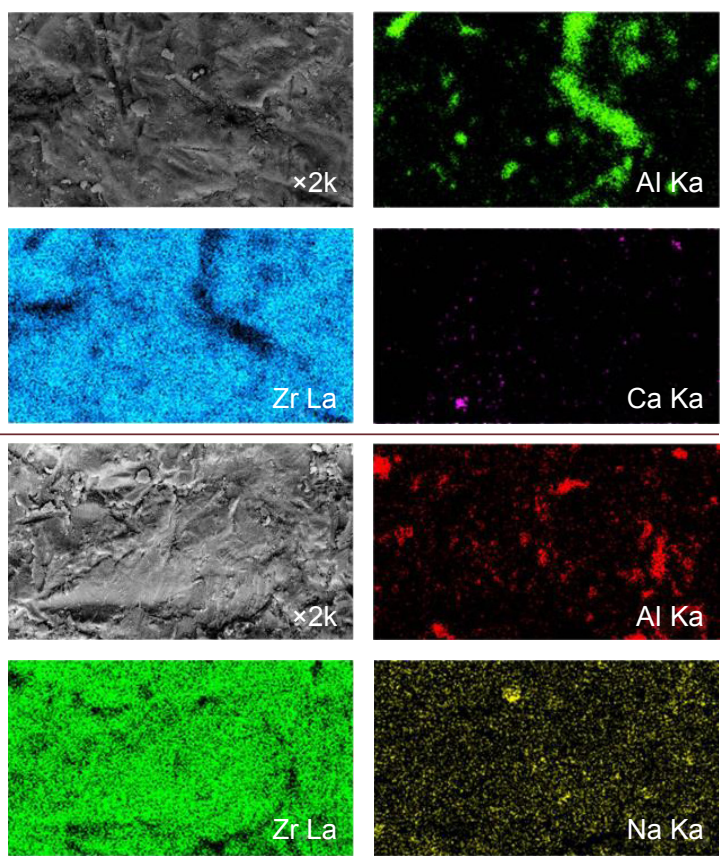

Figure 5 EDS mapping.

Notes: EDS mapping of the four coated Y-TZP surface under $\times 2,000$ magnifications, including $\mathrm{MgO}$-coated one (upper left), $\mathrm{Ca}(\mathrm{OH})_{2}-\mathrm{coated}$ one (upper right), $\mathrm{Zr}(\mathrm{OH})_{4}$ coated one (bottom left), and $\mathrm{NaOH}$-coated one (bottom right). Being the symbolic elements for different coatings, $\mathrm{Mg}$, $\mathrm{Ca}$, $\mathrm{Zr}$ and $\mathrm{Na}$ were detected on the coated surface respectively, which were presented as the highlight areas.

Abbreviations: EDS, energy dispersive spectrometer; Y-TZP, yttria-stabilized tetragonal zirconia polycrystals.

higher alkaline $\mathrm{pH}$ values using insoluble or slightly soluble alkaline compounds, a sufficient amount of a dispersible substance in a water suspension is needed. In our pilot study, micrometer-scaled $\mathrm{MgO}$ and $\mathrm{Zr}(\mathrm{OH})_{4}$ suspensions were used on zirconia surfaces to prepare alkaline coatings; unfortunately, powders were attached loosely on the coated Y-TZP surfaces after drying. The attachment remained loose even when using their water suspensions at a lower concentration.

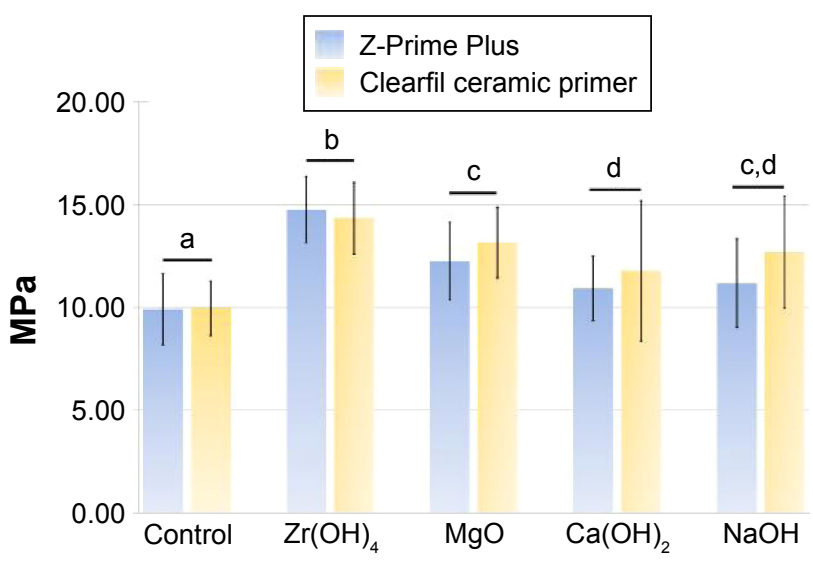

Figure 6 Mean and standard deviations of shear bond strength values for the ten groups.

Notes: Based on two-way ANOVA results, the horizontal bars above the columns indicate no significant difference between the two primers. The same letters above the horizontal bars indicate no significant difference based on different aging rates. Abbreviation: ANOVA, analysis of variance.
Moreover, a significant decrease in SBS caused by such coatings was found. This problem can be avoided by decreasing the sizes of the sparingly soluble $\mathrm{MgO}$ and insoluble $\mathrm{Zr}(\mathrm{OH})_{4}$ particles to the nano-scale because nano-scaled alkaline particles disperse in water like a colloidal sol. ${ }^{20,21}$ Nano-alkaline particles in such suspensions adhere to the zirconia surface through van der Waals' forces after drying. Consequently, the improvement of resin bonding of MDP to zirconia is possible with an alkaline coating prepared from insoluble or sparingly soluble alkaline compounds. A large number of particles with approximate sizes of several hundred nanometers are suspended in water after centrifugation for 10 minutes. These particles are still suspended in water after settling for 7 days; however, the particle sizes were dramatically reduced, indicating that centrifugation and 7 days settling removed most of the unstable aggregates. The resultant supernatants were comparatively stable for use as formation coatings. However, the sizes of $\mathrm{MgO}$ and $\mathrm{Zr}(\mathrm{OH})_{4}$ in the supernatants were still larger than their initial powder sizes (tens of nanometers), which suggested possible particle agglomeration in the water suspensions. Some methods, such as surface modification with sodium stearate or stearic acid, could be applied to prevent agglomeration of nano- $\mathrm{MgO}$ and $-\mathrm{Zr}(\mathrm{OH})_{4}$ particles in water supernatants. However, they were not used because of their uncertain 


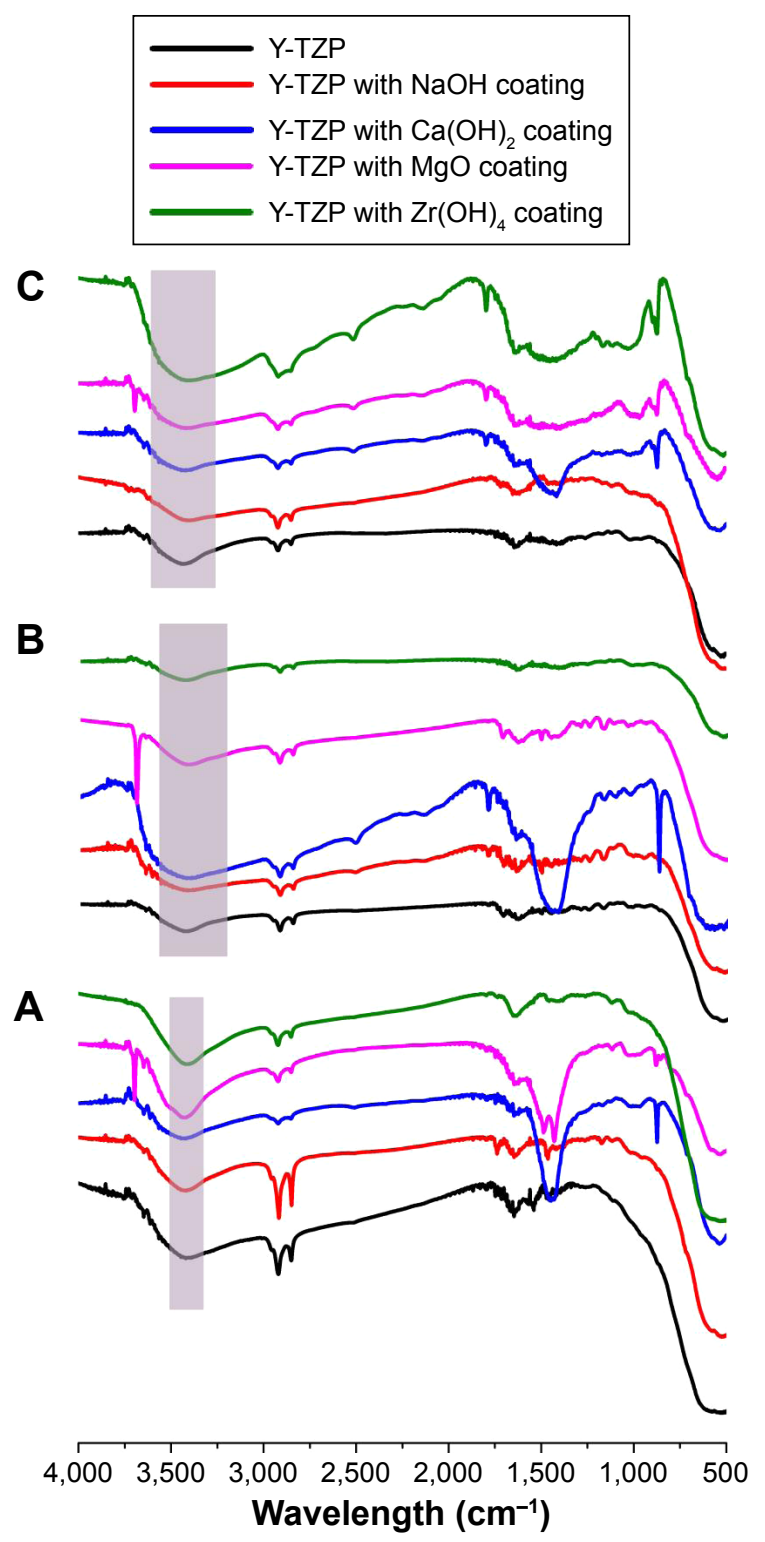

Figure 7 FTIR spectra.

Notes: (A) Y-TZP without MDP containing primers conditioning; (B) Y-TZP with Z-Primer Plus conditioning; (C) Y-TZP with Clearfil ceramic primer conditioning. Abbreviations: MDP, 10-methacryloyloxydecyldihydrogenphosphate; Y-TZP, yttria-stabilized tetragonal zirconia polycrystals.

effects on $\mathrm{pH}$ and because they might cause an unexpected interaction reaction with MDP. Fortunately, after 10 minutes of centrifugation and 7 days settling, suspensions of nano$\mathrm{MgO}$ or $-\mathrm{Zr}(\mathrm{OH})_{4}$ particles without surface modification were effectively used for coatings that improved resin bonding of MDP-conditioned Y-TZ; therefore, surface modification of nano- $\mathrm{MgO}$ and $-\mathrm{Zr}(\mathrm{OH})_{4}$ particles was unnecessary.

Using time-of-flight secondary ion mass spectroscopy, the "-P-O-Zr" bond was detected on Y-TZP surfaces conditioned with the MDP-containing primer, Z-Prime Plus. ${ }^{11}$ FTIR analysis supported the formation of a chemical bond between Y-TZP and MDP. More importantly, as the alkaline coating was prepared prior to application of a MDP-conditioning primer, $-\mathrm{OH}$ stretching peaks were strengthened; this provided the chemical evidence that alkaline coatings improve the coordination between MDP and $\mathrm{ZrO}_{2}$. However, no significant differences among different alkaline coatings can be detected by FTIR spectra.

Considering the SEM observations, nano-sized particles were scattered on the nano-MgO- or $-\mathrm{Zr}(\mathrm{OH})_{4}$-coated $\mathrm{Y}$-TZP surfaces, which are little centers that maintain the alkaline conditions of the Y-TZP surface. Similarly, scattered $\mathrm{NaOH}$ and $\mathrm{Ca}(\mathrm{OH})_{2}$ crystals were observed on the $\mathrm{NaOH}-$ and $\mathrm{Ca}(\mathrm{OH})_{2}$-coated Y-TZP surfaces, respectively; such crystals probably developed after the coatings were dried. These crystals were also little centers of alkaline conditions. The alkaline centers formed by nano- $\mathrm{MgO}$ or $-\mathrm{Zr}(\mathrm{OH})_{4}$ were stable in moist environments, but the alkaline centers formed by $\mathrm{NaOH}$ or $\mathrm{Ca}(\mathrm{OH})_{2}$ were unstable to moisture. In comparison with coatings comprising $\mathrm{NaOH}$ or $\mathrm{Ca}(\mathrm{OH})_{2}$, coatings comprising nano- $\mathrm{MgO}$ or $-\mathrm{Zr}(\mathrm{OH})_{4}$ particles provide more advantages for zirconia-based ceramic restorations.

The aforementioned thermodynamic and characterization results agree with the current SBS testing results, wherein all four alkaline coatings effectively improved the resin bond strength of MDP-conditioned Y-TZP. Therefore, this study validates our first null hypothesis, which stated that alkaline coatings improve resin bonding of MDP-containing primers to zirconia-based ceramic. The following four alkaline compounds tested in the present study were selected on the basis of their water solubility: $\mathrm{NaOH}$ (soluble), $\mathrm{Ca}(\mathrm{OH})_{2}$ (sparingly) soluble, $\mathrm{MgO}$ (sparingly soluble), and $\mathrm{Zr}(\mathrm{OH})_{4}$ (insoluble). The $1 \mathrm{~mol} / \mathrm{L} \mathrm{NaOH}$ solution showed the highest $\mathrm{pH}$ value. The saturated $\mathrm{Ca}(\mathrm{OH})_{2}$ solution had a slightly weaker $\mathrm{pH}$ value. The nano- $\mathrm{MgO}$ and $-\mathrm{Zr}(\mathrm{OH})_{4}$ suspensions had the lowest $\mathrm{pH}$ values. Contrary to the predicted order of the alkaline coatings on bonding as mentioned earlier, $\mathrm{NaOH}$ and $\mathrm{Ca}(\mathrm{OH})_{2}$ coatings with stronger alkaline conditions failed to provide the higher SBS. Rather, nano$\mathrm{MgO}$ or $-\mathrm{Zr}(\mathrm{OH})_{4}$ coatings with lower alkaline $\mathrm{pH}$ values provided a significantly higher SBS value compared to the $\mathrm{NaOH}$ and $\mathrm{Ca}(\mathrm{OH})_{2}$ coatings. We cannot reject the second null hypothesis that different $\mathrm{pH}$ values would not affect the promotion of alkaline coatings because increasing $\mathrm{pH}$ did not show a positive correlation with increased SBS values. The discrepancy between the thermodynamic calculations and the results of SBS test might come from the deviation of thermodynamic calculations. This was because that thermodynamic calculations were performed on the basis of the 
idealized models without completely simulating the real ones, besides, molecular dynamics cannot be considered in the thermodynamic calculations. Nevertheless, the aforementioned unexpected result is not bad news because the purpose of the present study was to find a water-resistant alkaline coating to promote resin bonding of MDP-containing primers to zirconia. The bonding improvement effected by insoluble nano- $\mathrm{Zr}(\mathrm{OH})_{4}$ and sparingly soluble nano-MgO coatings were better than the soluble alkaline coatings with higher $\mathrm{pH}$ values. These results suggest that preparing nano- $\mathrm{MgO}$ or $-\mathrm{Zr}(\mathrm{OH})_{4}$ coatings prior to conditioning with MDP-containing primers is potentially useful for improving resin bonding of zirconia in the clinic.

\section{Conclusion}

Based on the present study, and within its limitations, the following conclusions may be drawn:

1. Preparation of alkaline $\mathrm{NaOH}, \mathrm{Ca}(\mathrm{OH})_{2}, \mathrm{MgO}$, and $\mathrm{Zr}(\mathrm{OH})_{4}$ coatings improved the bonding of resin to zirconia conditioned with MDP-containing primers.

2. Higher alkaline $\mathrm{pH}$ values for MDP conditioning would not necessarily improve bonding.

3. Preparing nano-MgO or $-\mathrm{Zr}(\mathrm{OH})_{4}$ coatings prior to conditioning with MDP-containing primers is potentially valuable to further improve resin bonding of zirconia in the clinic.

\section{Acknowledgments}

This study was supported by grants 81400539, 2016YFA 0201704 from National Natural Science Foundation of China, CSA-B2015-04 from Chinese Stomatological Association, 2014-37, 15KJB320003 from Jiangsu Higher Education Institutions, and grants BK20140913 and BK20150998 from Natural Science Foundation of Jiangsu Province.

\section{Disclosure}

The authors report no conflicts of interest in this work.

\section{References}

1. Inokoshi M, De Munck J, Minakuchi S, Van Meerbeek B. Meta-analysis of bonding effectiveness to zirconia ceramics. J Dent Res. 2014;93(4): 329-334.
2. Özcan M, Bernasconi M. Adhesion to zirconia used for dental restorations: a systematic review and meta-analysis. J Adhes Dent. 2015;17(1):7-26.

3. Blatz MB, Sadan A, Kern M. Resin-ceramic bonding: a review of the literature. J Prosthet Dent. 2003;89(3):268-274.

4. Tzanakakis EC, Tzoutzas IG, Koidis PT. Is there a potential for durable adhesion to zirconia restorations? A systematic review. J Prosthet Dent. 2016;115(1):9-19.

5. Yoshida K, Tsuo Y, Atsuta M. Bonding of dual-cured resin cement to zirconia ceramic using phosphate acid ester monomer and zirconate coupler. J Biomed Mater Res B Appl Biomater. 2006;77(1):28-33.

6. de Souza G, Hennig D, Aggarwal A, Tam LE. The use of MDP-based materials for bonding to zirconia. J Prosthet Dent. 2014;112(4):895-902.

7. Amaral M, Belli R, Cesar PF, Valandro LF, Petschelt A, Lohbauer U. The potential of novel primers and universal adhesives to bond to zirconia. J Dent. 2014;42(1):90-98.

8. Yang B, Barloi A, Kern M. Influence of air-abrasion on zirconia ceramic bonding using an adhesive composite resin. Dent Mater. 2010;26(1): 44-50.

9. Kern M, Wegner SM. Bonding to zirconia ceramic: adhesion methods and their durability. Dent Mater. 1998;14(1):64-71.

10. Aboushelib MN, Matinlinna JP, Salameh Z, Ounsi H. Innovations in bonding to zirconia-based materials: part I. Dent Mater. 2008;24(9): 1268-1272.

11. Chen L, Suh BI, Brown D, Chen X. Bonding of primed zirconia ceramics: evidence of chemical bonding and improved bond strengths. Am J Dent. 2012;25(2):103-108.

12. Aboushelib MN, Mirmohamadi H, Matinlinna JP, Kukk E, Ounsi HF, Salameh Z. Innovations in bonding to zirconia-based materials. Part II: focusing on chemical interactions. Dent Mater. 2009;25(8):989-993.

13. Xie H, Li Q, Zhang F, et al. Comparison of resin bonding improvements to zirconia between one-bottle universal adhesives and tribochemical silica coating, which is better? Dent Mater. 2016;32(3):403-411.

14. Pilo R, Kaitsas V, Zinelis S, Eliades G. Interaction of zirconia primers with yttria-stabilized zirconia surfaces. Dent Mater. 2016;32(3):353-362.

15. Xie H, Tay FR, Zhang F, Lu Y, Shen S, Chen C. Coupling of 10-methacryloyloxydecyldihydrogenphosphate to tetragonal zirconia: effect of $\mathrm{pH}$ reaction conditions on coordinate bonding. Dent Mater. 2015;31(10):e218-e225.

16. Akin H, Tugut F, Akin GE, Guney U, Mutaf B. Effect of Er:YAG laser application on the shear bond strength and microleakage between resin cements and Y-TZP ceramics. Lasers Med Sci. 2012;27(2):333-338.

17. Kern M. Bonding to oxide ceramics-laboratory testing versus clinical outcome. Dent Mater. 2015;31(1):8-14.

18. Xie H, Li Q, Zhang F, et al. Comparison of bonding improvements to zirconia between one-bottle universal adhesives and tribochemical silica coating, which is better? Dent Mater. 2016;32(3):403-411.

19. Chen C, Chen G, Xie H, Dai W, Zhang F. Nano-silica coating for bonding improvements to zirconia. Int J Nanomed. 2013;8(1):4053-4062.

20. Choi SUS, Eastman JA. Enhancing thermal conductivity of fluids with nanoparticle. ASME International Mechanical Engineering Congress \& Exposition; 1995;231:99-106. Available from:https://www.researchgate.net/publication/236353373. Accessed September 15, 2016.

21. Lee S, Choi SUS, Li S, Eastman JA. Measuring thermal conductivity of fluids containing oxide nanoparticles. J Heat Transfer. 1999; 121(2):280-289.
International Journal of Nanomedicine

\section{Publish your work in this journal}

The International Journal of Nanomedicine is an international, peerreviewed journal focusing on the application of nanotechnology in diagnostics, therapeutics, and drug delivery systems throughout the biomedical field. This journal is indexed on PubMed Central, MedLine, CAS, SciSearch ${ }^{\circledR}$, Current Contents ${ }^{\circledR} /$ Clinical Medicine,

\section{Dovepress}

Journal Citation Reports/Science Edition, EMBase, Scopus and the Elsevier Bibliographic databases. The manuscript management system is completely online and includes a very quick and fair peer-review system, which is all easy to use. Visit http://www.dovepress.com/ testimonials.php to read real quotes from published authors. 